\title{
First Report of Rhodococcus Isolates Causing Pistachio Bushy Top Syndrome on 'UCB-1' Rootstock in California and Arizona
}

Rio A. Stamler and James Kilcrease, Department of Entomology, Plant Pathology, and Weed Science, New Mexico State University, Las Cruces, NM 88003; Craig Kallsen, University of California, Cooperative Extension, Bakersfield, CA 93307; Elizabeth J. Fichtner, University of California, Cooperative Extension, Tulare, CA 93274; Peter Cooke, Core University Resource Laboratory, New Mexico State University, Las Cruces, NM 88003; and Richard J. Heerema, Department of Plant and Environmental Sciences, and Jennifer J. Randall, Department of Entomology, Plant Pathology, and Weed Science, New Mexico State University, Las Cruces, NM 88003

\begin{abstract}
Stamler, R. A., Kilcrease, J., Kallsen, C., Fichtner, E. J., Cooke, P., Heerema, R. J., and Randall, J. J. 2015. First report of Rhodococcus isolates causing pistachio bushy top syndrome on 'UCB-1' rootstock in California and Arizona. Plant Dis. 99:1468-1476.

'UCB-1' (Pistacia atlantica $\times$ Pistacia integerrima) rootstock is a hybrid cultivar widely used by the U.S. pistachio industry. In the last three years, a large number of micropropagated UCB-1 pistachio rootstocks planted in California and Arizona orchards exhibited shortened internodes, stunted growth, swollen lateral buds, bushy/bunchy growth, stem galls with multiple buds, and twisted roots with minimal lateral branching. Field T-budding success in affected orchards was reduced to approximately $30 \%$ with unusual bark cracking often observed around the bud-union. The percentage of abnormal rootstocks within affected orchards varied from 10 to $90 \%$. We have termed the cumulative symptoms "pistachio

bushy top syndrome" (PBTS) to describe these affected trees. Two isolates, both containing virulence factors from the phytopathogen Rhodococcus fascians, were identified on symptomatic trees in field and nursery samples. Micropropagated UCB-1 trees inoculated with the Rhodococcus isolates exhibited stunted growth, shortened internode length, swollen lateral buds, sylleptic branching, and differences in root morphology, compared with control UCB-1 trees. To our knowledge, this is the first report of Rhodococcus isolates, related to Rhodococcus fascians, causing disease on a commercial tree crop and the results presented indicate that this organism is responsible at least in part for PBTS in California and Arizona.
\end{abstract}

Pistachio (Pistacia vera) is a tree nut crop in the cashew family (Anacardiaceae) native to south-central Asia, now with significant commercial production in Iran, China, the United States, Australia, and the Mediterranean region (FAO Statistics Division 2014). Within the United States, pistachio production is centered primarily in California's San Joaquin Valley with limited acreage in California's Sacramento Valley, Arizona, and New Mexico (USDA Census of Agric. 2012). United States pistachio production now exceeds 200,000 metric tons of in-shell-basis nuts per year, representing 1/5 of total world production, with a market value of well over U.S. $\$ 1$ billion annually (USDA-NASS 2014; FAO Statistics Division 2014). In response to strong global and domestic pistachio nut demand and resultant higher nut prices, planting of new orchards in the United States has accelerated in recent years. During the period of 2007-2012, new plantings occurred at a rate of 6400 ha per year in the United States, raising the total area to 94,000 ha (USDA Census of Agric. 2012).

Pistachio nuts are drupes with a hard endocarp or shell and fleshy mesocarp enclosing an oil-rich seed. Around the world, pistachio trees are propagated onto rootstocks of a number of Pistacia species, including $P$. vera, $P$. atlantica, $P$. integerrima, and $P$. terebinthus. Commercial pistachio cultivars in the United States are typically T-budded onto a rootstock in the field during the first summer

\section{Corresponding author: Jennifer J. Randall; Email: jrandall@nmsu.edu}

*The $\boldsymbol{e}$-Xtra logo stands for "electronic extra" and indicates that one supplementary figure is published online.

Accepted for publication 14 April 2015.

http://dx.doi.org/10.1094/PDIS-12-14-1340-RE

(C) 2015 The American Phytopathological Society after planting. Currently, interspecific hybrids of $P$. atlantica and $P$. integerrima are the most common rootstocks for new pistachio orchard plantings in the United States. One such hybrid rootstock cultivar, UCB-1 ( $P$. atlantica $\times P$. integerrima), developed by the University of California-Berkley, is popular due to its excellent resistance to Verticillium wilt, moderate level of cold tolerance, and exceptional vigor with 'Kerman' as a scion cultivar (Ferguson, 2008; Morgan et al. 1992). UCB-1 rootstocks are often grown from seed, but even with closed pollination, off-type phenotypes in UCB-1 seedlings occur due to differential allele segregation and contaminated pollen during seed propagation (Ahmad et al. 2005). Clonal propagation of UCB-1 rootstock via tissue culture was developed in order to eliminate genetic variability and allow for the selection of superior UCB-1 clones (Almehdi et al. 2002).

Since 2011, a large number of micropropagated UCB-1 pistachio rootstocks newly planted in California and Arizona have exhibited symptoms including stem galls, shortened internodes, stunted growth, swollen lateral buds, bushy/bunchy growth of foliage, and twisted roots with reduced lateral branching. This bushy growth in young trees is atypical since Pistacia species are strongly apically dominant (Spann et al. 2007). The percentage of abnormal rootstocks within affected orchards varied from 10 to $90 \%$ with approximately $30 \%$ budding success to affected trees in the field. As early as the same year of T-budding, many trees exhibited excessive bark cracking around the bud union. The term "pistachio bushy-top syndrome" (PBTS) is now used to describe the suite of symptoms exhibited by these trees. Conservative estimates indicate that approximately one million trees from 14,000 hectares from existing nonbearing orchards are exhibiting PBTS symptoms and are in the process of being removed.

Rhodococcus fascians, previously known as Corynebacterium fascians, is a gram-positive bacterial plant pathogen with a host range encompassing over 40 plant families (Putnam and Miller 2007). Symptoms due to this bacterium are often confused with those caused 
by phytoplasmas, viruses, Agrobacterium tumefaciens, or latent hormone effects. Infected plants exhibit symptoms including stunted growth; shortened internodes; abnormal shoot proliferation or witches broom; leafy galls; misshapen, thickened leaves or shoots; and modified root development (Putnam and Miller 2007). R. fascians can be present as an epiphyte on asymptomatic plants or may gain entry into the plant tissues where it modulates phytohormone activity (Cornelis et al. 2001; Maes et al. 2001). Although $R$. fascians typically causes disease on herbaceous perennials (Putnam and Miller 2007), it has been reported on a small number of trees and shrubs from nurseries, suggesting that woody perennials may be at risk of infection where both woody and nonwoody species are produced in the same location (Miller and Putnam 2010; Quoirin et al. 2004).

The model proposed for the interaction of $R$. fascians with its host has been based on a single isolate (strain D188), which carries a large linear plasmid ( $\mathrm{pFiD188}$ ) containing genes essential for virulence and thought to be involved in cytokinin synthesis (Creason et al. 2014; Crespi et al. 1992; Stes et al. 2011; Stes et al. 2013; Pertry et al. 2009; Pertry et al. 2010). Current molecular detection of $R$. fascians relies on extraction of DNA directly from affected plant material or bacterial enrichment on selective media followed by amplification of virulence genes including vicA, fasA, and fas D (Nikolaeva et al. 2012; Serdani et al. 2013). FasA and fasD encode putative $\mathrm{P} 450$ cytochrome monooxygenase and isopentenyl transferase (ipt), respectively; in strain D188, both genes are located on the linear plasmid and are involved in the production of a mixture of active cytokinins that affect plant hormonal levels, leading to leafy galls (Pertry et al. 2009; 2010). The chromosomal gene vicA, required for in-planta growth on symptomatic tissue, encodes malate synthase, which functions in the glyoxylate shunt of the TCA cycle (Vereecke et al. 2002). VicA is part of an 18-kb gene cluster that is syntenic with a Mycobacterium tuberculosis locus essential for chronic persistence in animal hosts (Vereecke et al. 2002).

Here, we present the initial characterization of two Rhodococcus strains isolated from PBTS UCB-1 pistachio rootstock and demonstrate their pathogenicity on micropropagated UCB-1 rootstock trees in a greenhouse environment. The bacteria were identified through selective culture techniques and sequence analysis in clonal UCB-1 rootstock from 14 PBTS-affected orchards in California and Arizona as well as from commercial nursery stock in California.

\section{Materials and Methods}

Sample collection. Tissue samples were collected from asymptomatic and PBTS-symptomatic UCB-1 rootstock trees in 14 independent orchards in California and Arizona, and four commercial nursery sources. Samples were collected using pruning shears that were surface disinfested with $70 \%$ ethanol or benzalkonium chloridebased disinfectant (Lysol, Reckitt Benckiser, Slough, Berkshire, UK). Vinyl gloves were changed between trees or hands were washed with ethanol between trees. Samples were placed in plastic zippered storage bags (S.C. Johnson and Sons, Racine, WI) and kept on ice prior to mailing by overnight courier to New Mexico State University (NMSU). Global positioning system coordinates were recorded for each orchard location. Orchard samples consisted of leaves, stems, and roots. Commercial nurseries shipped potted trees directly to NMSU using overnight delivery. The trees were maintained in a quarantine facility greenhouse at NMSU.

Bacterial culturing. Fresh leaf tissue was printed directly onto D2 media (Kado and Heskett 1970) or mD2 media (D2 medium with $40 \mathrm{mg} /$ liter of polymyxin B sulfate and $0.4 \mathrm{mg} /$ liter of sodium azide [VWR, Radnor, PA]). Additional plant tissue was surface disinfected in $0.6 \%$ sodium hypochlorite for $20 \mathrm{~s}$ followed by $1 \mathrm{~min}$ in $70 \%$ ethanol and three rinses with deionized (DI) water. The tissue was then ground and diluted in water or D2 broth prior to plating on D2 media. Plates were incubated at $27^{\circ} \mathrm{C}$ for 4 to 10 days. Bacterial growth was restreaked for single-colony isolation.

Transmission electron microscopy. Bacteria grown on D2 plates were suspended in sterile DI water and stained with uranyl acetate on a carbon formvar-coated grid. The grid was visualized on a Hitachi H-7650 transmission electron microscope (Hitachi LTD, Tokyo, Japan).
Confocal microscopy. Petiole tissue from UCB-1 trees inoculated with both Rhodococcus isolates was harvested 120 days postinoculation. Tissue was cut into 1- to 4-mm sections using a sterile scalpel blade and stained with the LIVE/DEAD BacLight Bacterial Viability Kit (Life Technologies, Carlsbad, CA). Glutaraldehyde was then added to a final concentration of $2.5 \%$. Tissue was imaged using a TCS SP5 II Broadband Confocal Microscope (Leica Microsystems, Wetzlar, Germany), utilizing a 488-nm argon laser and emission windows set to $500 \mathrm{~nm}( \pm 50 \mathrm{~nm})$ and $635 \mathrm{~nm}( \pm 50 \mathrm{~nm})$ to match the emission spectra of SYTO 9 and propidium iodide, respectively. A maximum-intensity projection image was generated with false color for the two channels specified.

Scanning electron microscopy. Bacterial cultures were suspended in sterile water and added to a freshly cleaned glass coverslip and briefly air-dried. Each sample was immersed in $2 \mathrm{ml}$ 0.1-M imidazole HCL with $2.5 \%$ glutaraldehyde, and dehydrated in a serial ethanol gradient series with a final incubation in hexamethyldisilazane. Samples were air-dried and sputter-coated with gold. Secondary electron images were generated using a S-3400 N II scanning electron microscope (Hitachi LTD, Tokyo, Japan).

Gram stain determination. Bacteria grown on $\mathrm{D} 2$ or $\mathrm{mD} 2$ were heat fixed onto glass slides and gram stain procedures were performed according to the manufacturer's instructions (Hardy Diagnostics, Santa Maria, CA).

Bacterial genomic DNA isolation. Bacterial genomic DNA was isolated from orange and yellow-orange gram-positive colonies using UltraClean Microbial DNA Isolation Kit (MO Bio Laboratories, Carlsbad, CA). DNA was visualized on a $1 \%$ agarose gel stained with ethidium bromide and documented on a GelDoc-It imager (UVP Upland, CA)

Plant genomic DNA isolation. Total plant DNA was isolated from leaves, stems, and roots of symptomatic and asymptomatic UCB-1 plants. Tissues were ground in liquid nitrogen with a mortar and pestle and extracts processed using DNeasy Plant kits (Qiagen N.V. Limburg, Netherlands). Isolated DNA was stored at $-20^{\circ} \mathrm{C}$.

Molecular tests with bacterial and plant genomic DNA. Bacterial genomic DNA and plant genomic DNA was screened using 16S rDNA primers and chromosomal virulence-locus vicA primers (Nikolaeva et al. 2012) using published cycle times. Diagnostic PCR primer sets previously developed for $R$. fascians virulence genes were also utilized, including RF 229/RF 408 (Nikolaeva et al. 2012); FasF/R and p450F/R (Serdani et al. 2013). Nearest-neighbor phylogenetic trees were generated with the HKY algorithm using Geneious software version 6.0.6 (Biomatters, Auckland, New Zealand).

Koch's postulates with UCB-1 rootstock trees. Unbudded clonal UCB-1 trees in plugs were purchased from a commercial supplier recently acclimated (eight weeks) out of tissue culture (Fig. 5A). Trees were screened for the presence of Rhodococcus prior to inoculation by plating leaf tissue on selective $\mathrm{mD} 2$ medium and by total DNA isolation from plant tissue. Three trials were performed, each with 16 plants in each treatment. In the first trial, Rhodococcus isolate 2 grown on $\mathrm{mD} 2$ plates was suspended in a $0.01 \mathrm{M}$ phosphate buffer $\mathrm{pH} 7.0$ at an OD of 0.7 , and $20 \mathrm{ml}$ were sprayed on UCB-1 trees in plugs and subsequently sprayed for two additional days with $10 \mathrm{ml}$ of the Rhodococcus isolate 2 suspension. The mock-inoculated controls corresponded to UCB-1 trees sprayed with $20 \mathrm{ml}$ of $0.01-\mathrm{M}$ phosphate buffer $\mathrm{pH} 7.0$ the first day and subsequently sprayed with $10 \mathrm{ml}$ of $0.01-\mathrm{M}$ phosphate buffer for two days. All trees were maintained in a humidity chamber under fluorescent lights for two weeks. Rootstocks were transplanted into 20 -cm pots two weeks after inoculation and plants were maintained in a quarantine greenhouse for the duration of the experiment. The greenhouse was maintained at a temperature of 28 to $30^{\circ} \mathrm{C}$. Plants were maintained at a 16 -h photoperiod and watered every third day. The second and third trial included four treatments: (i) mock-inoculated control; (ii) inoculated with Rhodococcus isolate 1; (iii) inoculated with Rhodococcus isolate 2 ; and (iv) inoculated with both Rhodococcus isolates 1 and 2. Control plants were treated by spraying $10 \mathrm{ml}$ of $10 \mathrm{mM} \mathrm{MgCl} 2$ and $10 \mathrm{mM}$ MES. For each of the inoculation treatments, Rhodococcus isolate 1 or 2 was scraped from D2 plates and suspended in $10 \mathrm{mM}$ $\mathrm{MgCl}_{2}$ and MES to an $\mathrm{OD}_{600}$ of 0.7 . Each bacterial suspension was 
added to its own individual spray bottle, and $10 \mathrm{ml}$ was applied to each tree. A combination of equal volumes of Rhodococcus isolates 1 and 2 were mixed in a spray bottle to a final $\mathrm{OD}_{600}$ of 0.7 and $10 \mathrm{ml}$ of the combined suspension was applied to each plant. The trees in the second and third trial were only sprayed once as compared with the first trial. Plants from all treatments remained in humidity chambers under growth lights for two weeks prior to being transplanted into $20 \mathrm{~cm}$ pots and moved to a quarantine greenhouse. Plants were monitored and photos were taken periodically. Height, number of internodes, and number of shoots were measured for each plant at three time-points during the experiment. Statistical significance of $P<0.05$ was determined using Tukey-Kramer test with Satterthwaite adjustment (SAS 9.2; SAS Institute Inc., Cary, NC) mixed linear model procedure.

\section{Results}

Symptoms of pistachio bushy top syndrome. Orchards planted with clonal UCB-1 rootstocks from 2011-2014 in Arizona and California exhibited symptoms that included severe stunting (Fig. 1A). These trees had shortened internode length and substantial sylleptic branching due to a loss of apical dominance that gives rise to a bushy appearance (Fig. 1A, B). Affected trees had swollen lateral buds that, after pruning, often gave rise to stem galls with multiple buds or shoots emerging from the swollen tissues (Fig. 1C, D, G, H). The length of time for gall development varied between orchards, but was as short as 8 months after planting in one orchard in Kern County, CA. The root systems on these trees were also stunted with twisted structural roots and minimal lateral branching (Fig. 1F). Poor root development allowed for trees to be blown over by heavy winds and many of these trees could be easily pulled from the ground by hand up to three years after planting. The UCB-1 rootstock trees that exhibited these symptoms had an estimated $30 \%$ success rate for compatible T-budding to $P$. vera scion compared with the typical $90 \%$ success rate of budding. Affected trees that were successfully T-budded often had an unusual bark cracking around the graft union, which developed anywhere from 2 months to 3 years after budding (Fig. 1C, E). The percentage of abnormal UCB-1 rootstocks within affected orchards varied from 10 to $90 \%$.
Initial detection of Rhodococcus DNA sequence in symptomatic UCB-1 tree samples. Total DNA isolated from UCB-1 rootstocks exhibiting PBTS was used as template for amplification with $16 \mathrm{~S}$ rDNA primers to check for bacterial DNA. Sequence analysis of multiple 16S PCR amplicons from symptomatic field samples and from a commercial source identified sequences that had 89 to $99 \%$ identity to Rhodococcus sp. A representative sequence, generated from a symptomatic UCB-1 tree and deposited into GenBank (Accession No. KJ677036) had $99 \%$ identity to $R$. corynebacterioides. Using the same plant DNA as template, the $R$. fascians species-specific vicA diagnostic primer set (Nikolaeva et al. 2012) generated an amplicon that had $99 \%$ identity to R. fascians (Accession No. KJ677035). Subsequent screening of total DNA from PBTS-affected field samples and a commercial source generated multiple vicA amplicons that grouped with $R$. fascians on a highly supported branch containing multiple subclades (Fig. 2B). Multiple phenotypically normal orchards, nonbearing and mature, did not generate $R$. fascians vicA sequence when screened in the same fashion.

Isolation and morphological characterization of bacterial isolates associated with PBTS. Epiphytic and endophytic bacteria were isolated from nonaffected orchard trees, symptomatic and asymptomatic trees from PBTS-affected orchards, and from clonal UCB-1 asymptomatic and symptomatic nursery trees obtained from commercial sources. Leaves were used directly for prints (Fig. 3A) or surface sterilized and ground and plated on semiselective media. Many of the leaf prints resulted in a copious amount of fungal growth, and some bacterial colonies. Smooth cream-pigmented bacterial colonies were cultured from all UCB-1 samples and these colonies were not identified. Leaf prints from many symptomatic and asymptomatic samples from PBTS orchards produced yellow- and orange-pigmented bacteria (Fig. 3B). Pigmented bacteria were also cultured from symptomatic leaf tissue that was surface sterilized prior to isolation (Table 1). No orange-yellow colonies were obtained from leaf prints or internal tissues of trees in nonaffected orchards (Table 1). Orange-yellow colonies were cultured from only one commercial source from symptomatic and asymptomatic trees. Based on pigment color and cell morphology, two distinct coryneform cultures were

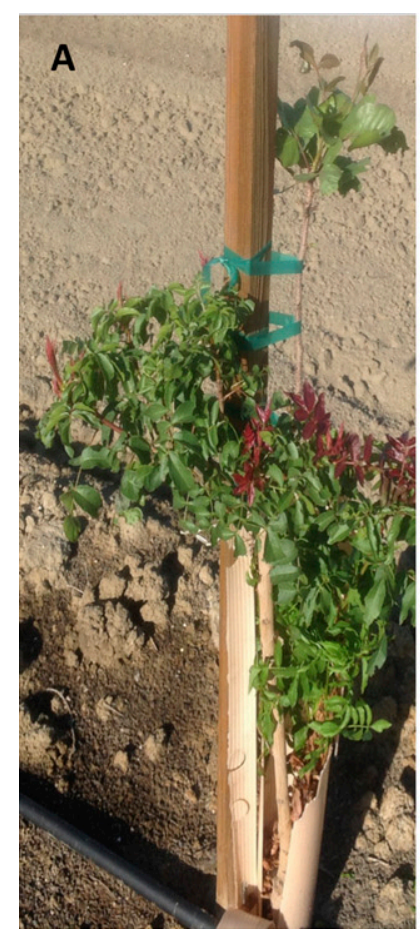

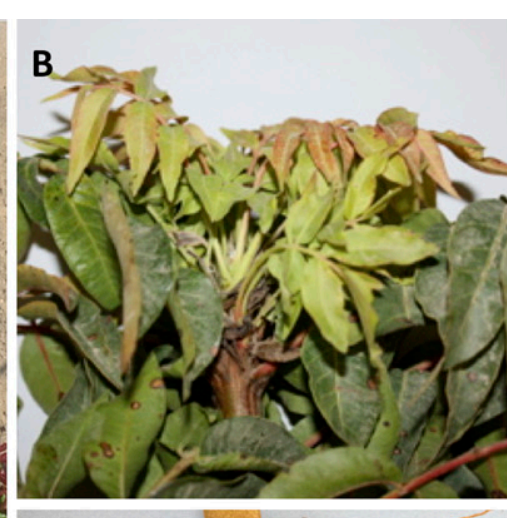

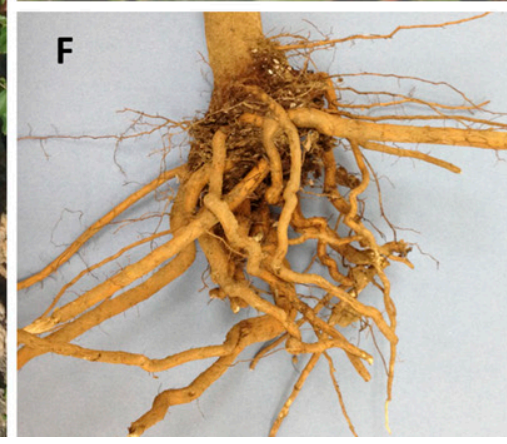

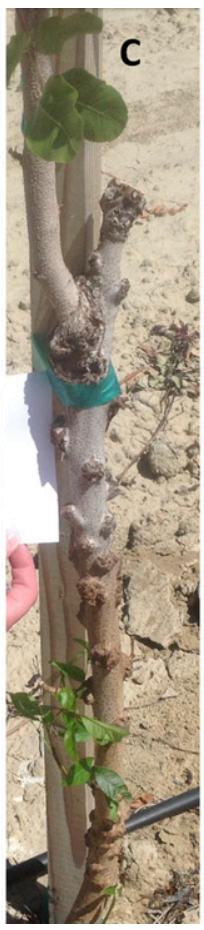
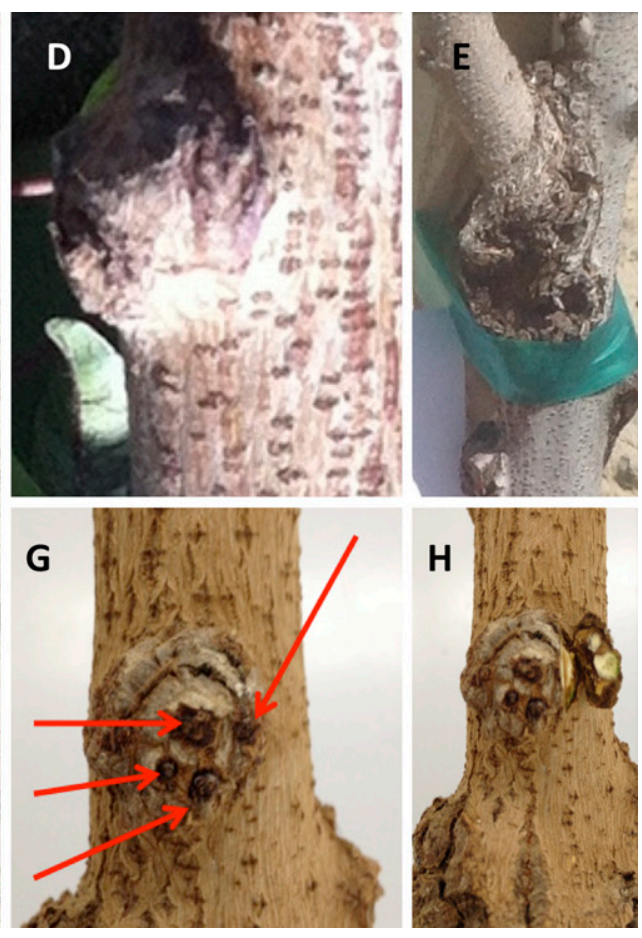

Fig. 1. Phenotypes of UCB-1 rootstock trees exhibiting pistachio bushy top symptoms from affected orchards. A, Stunted UCB-1 clonal tree planted one year prior to picture. B, UCB-1 rootstock with bushy top. C, UCB-1 tree planted in 2012 with stem galls (indicated by arrows). D, UCB-1 tree planted in 2013 with enlarged lateral bud. E, Cracking at the bud union of short UCB-1 planted in 2013. Tree grafted with Kerman. F, Root of a UCB-1 tree planted in 2012. G and H, Buds (indicated by arrows in G) emerging from stem gall on UCB-1 trees. 
consistently isolated from PBTS-affected samples from the surface and from internal tissues and a representative isolate for each was selected for further analysis. Rhodococcus sp. strain 1 (referred to as isolate 1) is pigmented with a bright orange color and the other, Rhodococcus sp. strain 2 (referred to as isolate 2), is pigmented with a yellow-orange color (Fig. 3B, C, D). Both bacterial cultures are gram-positive with pleomorphic rod- and club-shaped cells that are smooth and convex with no discernable differences between the two cultures when viewed with light, scanning electron, and transmission electron microscopy (Fig. 3E, F, G, H).

Multilocus sequence analysis of both Rhodococcus isolates associated with PBTS. Genetic analyses were performed on representative bacterial cultures isolated from symptomatic PBTS rootstocks. Based on 16S rDNA sequence analysis, both isolates are distinct members of the genus Rhodococcus. Isolate 1 (bright orange pigment) is $99 \%$ identical to $R$. corynebacterioides (GenBank Accession No. KP274061), and isolate 2 (yellow-orange pigment) is $99 \%$ identical to $R$. fascians (Accession No. KP274065) when considering the $16 \mathrm{~S}$ rDNA sequence (Fig. 2A). The vicA (malate synthase) sequences from isolate 1 (Accession No. KP274063) and isolate 2 (Accession No. KP274066) are $97 \%$ and $99 \%$ identical to R. fascians D188, respectively, and form two distinct, well-supported phylogenetic clades (Fig. 2B). All additional vicA sequences generated from bacteria isolated from PBTS symptomatic trees in California and Arizona group into the two clades defined by isolate 1 and 2 (Fig. 2B). The two Rhodococcus isolates were screened with diagnostic primer sets that amplify virulence genes found on the pFiD188 plasmid (Nikolaeva et al. 2012; Serdani et al. 2013). Both isolates generated fasD (isopentenyl transferase) sequences that had $100 \%$ identity to pFiD188 (Accession Nos. KP274064 and KP274067) and isolate 1 generated fas A (putative p450 monooxygenase) sequence that had $100 \%$ identity to pFiD188 (Accession No. KP274062). At the time of publication, no fas $A$ sequence was generated for isolate 2 .

Koch's postulates with Rhodococcus isolate 1 and Rhodococcus isolate 2 on clonal UCB-1 pistachio. UCB-1 clonal rootstock trees used for completion of Koch's postulates were uniform in size (Fig.
5A) and Rhodococcus was not detected from these plants (data not shown). The mock-inoculated control trees grew at a consistent rate throughout the experiment and maintained an approximately constant internode length (Fig. 4A and C, Fig. 5B). Control trees were apically dominant (Fig. 5B, Fig. 6A) and had normal root morphology at 100 days postinoculation (DPI) (Fig. 7A). Trees inoculated with Rhodococcus isolate 1 or isolate 2 individually had similar growth rates as control trees for the first 40 DPI but subsequently slowed significantly and were on average $14 \mathrm{~cm}$ shorter than control trees by 100 DPI (Fig. 4A, B). Trees that were coinoculated with both Rhodococcus isolates grew at a slower rate than control trees for the duration of the experiment and by 100 DPI the average height difference between coinoculated and control plants was $26 \mathrm{~cm}$ (Fig. 4A and B, Fig. 5B and C). At $100 \mathrm{DPI}$, the average internode length was significantly reduced for trees inoculated with Rhodococcus isolate 2 but not isolate 1 (Fig. 4C). Average internode length for trees coinoculated with both Rhodococcus isolates was significantly shorter than single-inoculated or control trees (Fig. 4C). Trees inoculated with Rhodococcus isolate 2 exhibited pronounced sylleptic branching (Fig. 6B) and swollen lateral buds (Fig. 6G) at 100 DPI, which was not observed in control trees (Fig. 6A). Inoculated trees also exhibited other morphological differences such as small, light-green colored leaves that were often twisted or cupped and wrinkled in appearance (Fig. 6C), stunted growth (Fig. 6D), loss of apical dominance (Fig. 6E), and abnormal apical meristems (Fig. 6I) (Table 2). Slight, dark lesions were also observed on the stems of inoculated plants (Fig. 6F). Root systems on control plants showed both structural and lateral root growth (Fig. 7A), whereas root systems of inoculated plants were poorly developed (Fig. 7B) and showed abnormal twisting not observed on control plants (Fig. 7C, D, E). Symptoms observed are listed in Table 2 . The frequency of incidence of symptom development was measured as trees having two or more symptoms listed in Table 2 and were consistent in all three trials (Table 3). To complete Koch's postulates, both Rhodococcus isolates were reisolated from inoculated plants and colony identities were confirmed through vicA amplification. Sequence analysis on selected colonies confirmed that the vicA
A

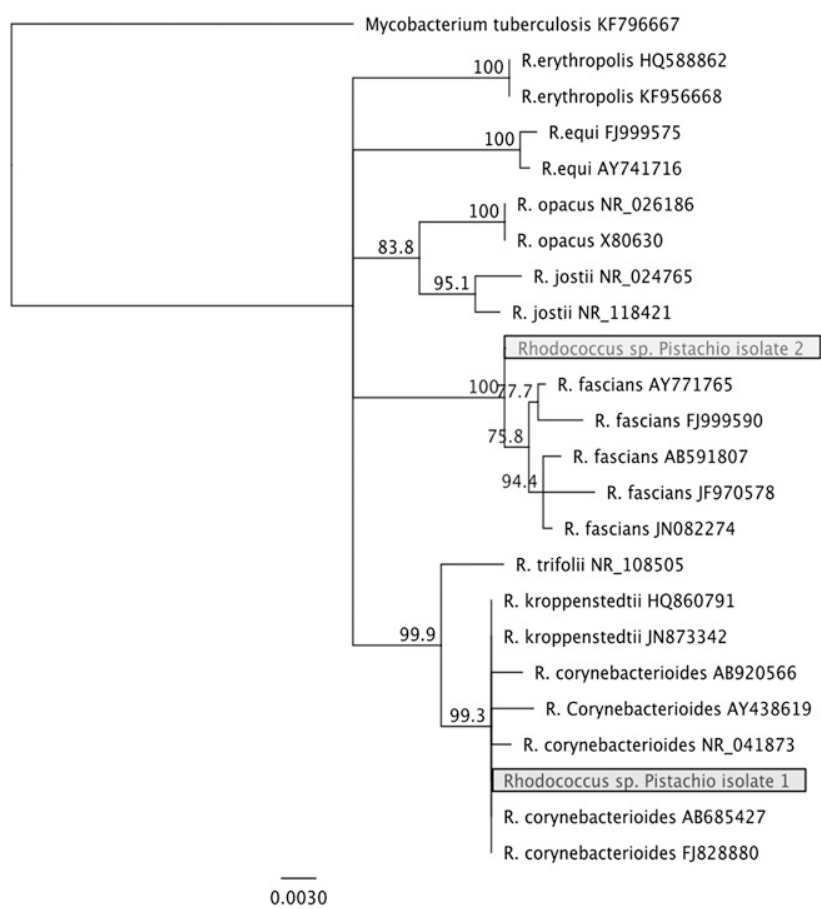

B

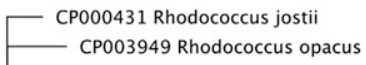

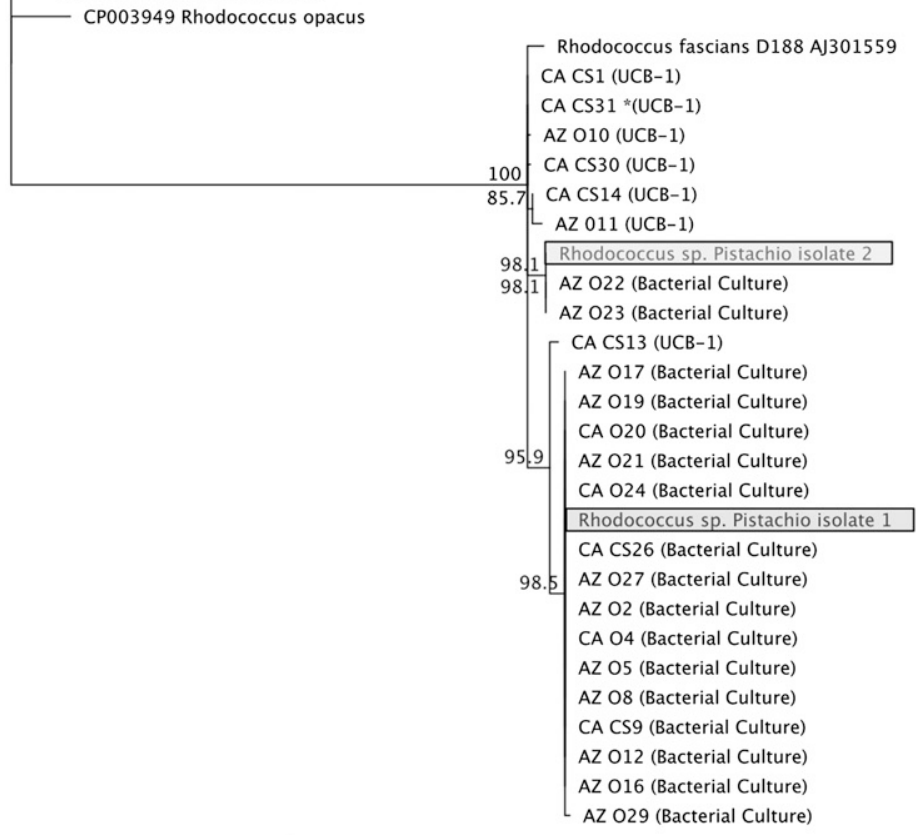

0.0030

Fig. 2. Multilocus phylogenetic analysis of Rhodococcus spp. isolated from PBTS trees in Arizona and California. Nearest neighbor phylogenetic trees based on DNA sequence, constructed using the HKY algorithm, bootstrapped $1000 \times$ with a support threshold of $70 \%$. A, Rhodococcus spp. pistachio isolates 1 and 2 correspond to reference sequences with GenBank accession numbers listed in text. 16S rDNA sequences amplified from Rhodococcus sp. isolate 1, Rhodococcus sp. isolate 2, or obtained from GenBank. B, vicA (malate synthase) sequences amplified from bacterial culture and symptomatic UCB-1 tissue, or obtained from GenBank. Samples are labeled by state of origin (CA or AZ), orchard sample (O) or commercial source (CS), and isolate number. 
sequence was identical to that of isolates 1 and 2 and consistent with inoculum source (Fig. 4D). Confocal microscopy at 120 DPI, identified multiple clusters of viable coryneform bacteria on the surface of petiole tissue inoculated with both Rhodococcus isolates (Fig. 4E).

\section{Discussion}

A significant number of UCB-1 rootstock trees planted between 2011 and 2014 in Arizona and California exhibited delays in growth due to severe morphological abnormalities. These abnormal trees exhibited symptoms that included stunting, shortened internodes, bushy-top appearance, swollen nodes, and twisted and stunted root systems. Pruning sucker branches resulted in the formation of stem galls, which contained multiple buds or shoots emerging from the swollen stem tissue. The root systems of affected trees had major twisting with little lateral root growth. This type of root growth is abnormal for pistachio trees, as they are known to be phreatophytes,

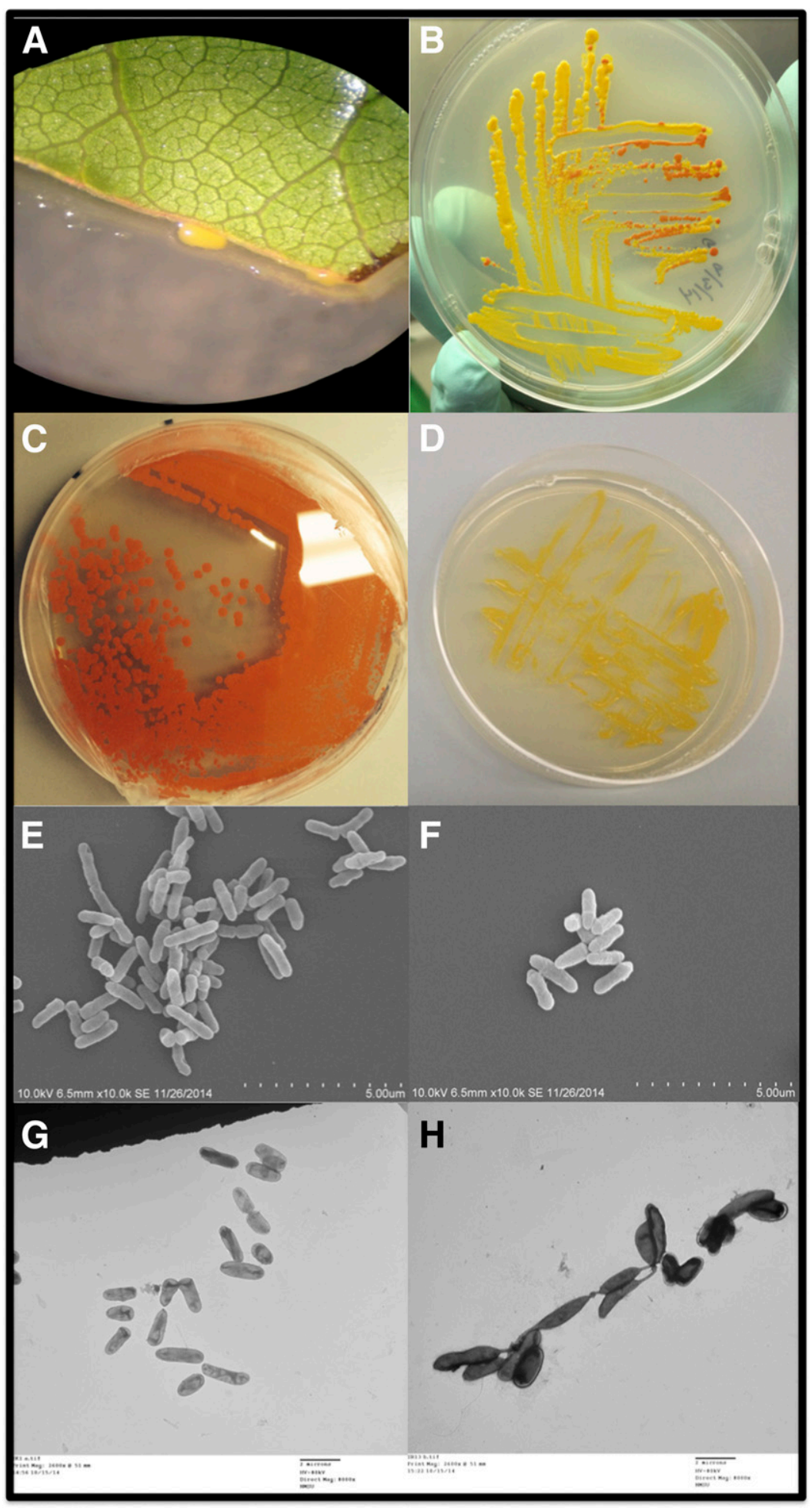

Fig. 3. Rhodococcus spp. cultures from PBTS trees. A, Leaf print with Rhodococcus growing from the leaf onto the selective media. B, Bacteria culture showing both orange and chrome (yellow-orange) Rhodococcus isolates. C, Rhodococcus isolate 1 cultured onto D2 media. D, Rhodococcus isolate 2 cultured onto D2 media. E, Scanning electron microscopy image of Rhodococcus isolate 1. F, Scanning electron microscopy image of Rhodococcus isolate 2. G, Transmission electron microscopy of Rhodococcus isolate 1. Scale bar represents 2 microns. H, Transmission electron microscopy of Rhodococcus isolate 2 . Scale bar represents 2 microns. 
in which roots spread out extensively through soil to obtain water and nutrients (Ferguson et al. 2005). In PBTS-affected orchards in Arizona, three-year-old trees with twisted and underdeveloped root systems fell over due to high winds. In Arizona and California, many three- and four-year-old UCB-1 trees could be easily removed from the soil by hand, demonstrating a poor root system.

Symptom development in affected fields was difficult to predict and many trees labeled as 'normal' failed to promote vigorous scion growth.
Some asymptomatic trees (Supplementary Fig. 1) within orchards containing PBTS-affected trees tested positive either by testing total DNA for Rhodococcus sequence or by culturing Rhodococcus spp. These same trees began to display symptoms three to four months later. $R$. fascians is known to have an epiphytic phase prior to plant ingress and initiation of symptoms (Cornelis et al. 2001; Maes et al. 2001).

Two distinct Rhodococcus cultures were consistently isolated from PBTS UCB-1 rootstock trees. While $16 \mathrm{~S}$ rDNA sequence

Table 1. Rhodococcus spp. isolated from UCB-1 samples

\begin{tabular}{lcc}
\hline Source & $\begin{array}{c}\text { Percentage of symptomatic UCB-1 } \\
\text { trees tested positive for Rhodococcus }\end{array}$ & $\begin{array}{c}\text { Percentage of asymptomatic } \\
\text { UCB-1 trees tested positive } \\
\text { for Rhodococcus }\end{array}$ \\
\hline CA and AZ orchards & $81 \%$ & $\begin{array}{c}\text { UCB-1 trees tested with no symptom } \\
\text { data. Samples often batched and } \\
\text { represent up to 10 trees }\end{array}$ \\
with PBTS symptoms & $61 / 75$ & $33 \%$ \\
CA and AZ orchards with & N/A & $15 / 45$ \\
no observed symptoms & & $0 \%$ \\
\hline
\end{tabular}

\section{A Rhodococcus isolates inhibit 'UCB-1' Rootstock Growth}

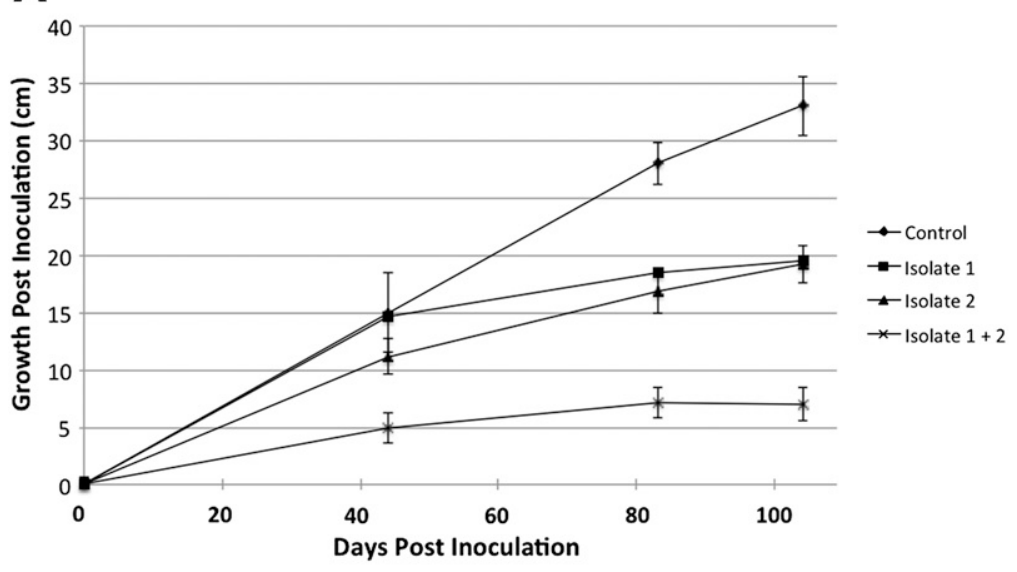

B

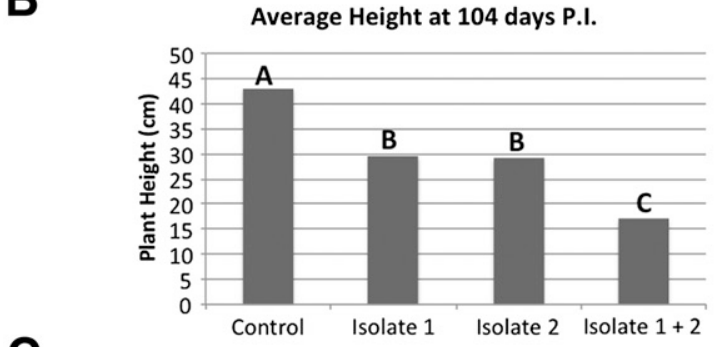

Average Internode Length at 104 days P.I.

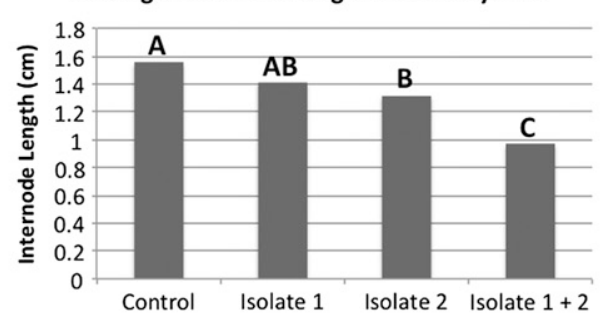

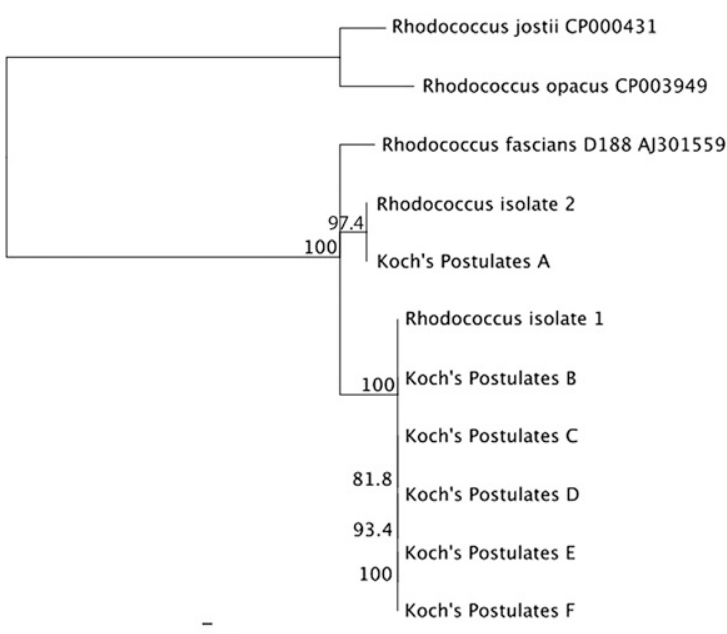

0.0030

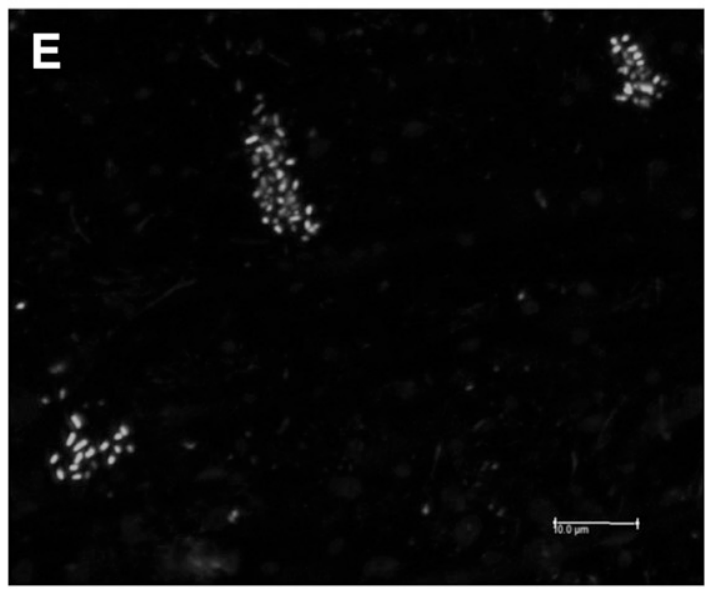

Fig. 4. Koch's Postulates using clonal UCB-1 trees, transitioned out of tissue culture eight weeks prior to inoculation with Rhodococcus isolates 1 and 2 . Four treatments were performed with 16 plants per treatment for each trial. The control plants were mock-inoculated with buffer. Three inoculated treatments included bacterial suspensions of Rhodococcus isolate 1, Rhodococcus isolate 2, and both Rhodococcus isolate 1 and isolate 2. A, Growth curves showing height of UCB-1 plants at multiple time points after inoculation. Error bars are standard error $(n=16)$. B, The average height of each treatment is shown at 104 days post-inoculation. Statistical significance between control and inoculated treatments at $P \leq 0.05$ was determined using the Tukey-Kramer test with Satterthwaite adjustment (SAS 9.2; SAS Institute Inc., Cary, NC) mixed linear model procedure. C, The average internode length $(\mathrm{cm})$ of each treatment is shown at 104 days post-inoculation. Statistical significance between control and inoculated treatments at $P \leq 0.05$ was determined using the Tukey-Kramer test with Satterthwaite adjustment (SAS 9.2) mixed linear model procedure. D, Nearest-neighbor phylogenetic tree of vicA nucleotide sequences generated from trials on UCB-1. Rhodococcus bacterial cultures reisolated from inoculated plants (A, isolate 2-inoculated plants; B, isolate 1-inoculated plants; C, D, E, and F, isolate 1+2-inoculated plants). E, Confocal microscopy of the outside of a UCB-1 petiole inoculated with Rhodococcus isolate 1 and 2 at $120 \mathrm{DPI}$. Sample was stained with LIVE/DEAD and indicates viable bacteria. 
indicated they are distinct species of Rhodococcus, the vicA sequence for both isolates was highly similar to that of $R$. fascians (D188) (Fig. 2 ). However, $16 \mathrm{~S}$ rDNA is known to be a problematic means for identification of Rhodococcus sp. (Gürtler et al. 2004). Several studies suggest that virulence of Rhodococcus fascians is at least partially dependent upon the presence of specific genes on a linear plasmid (Crespi et al. 1992; Crespi et al. 1994). Some of these virulence sequences were identified in Rhodococcus isolate 1 and 2.

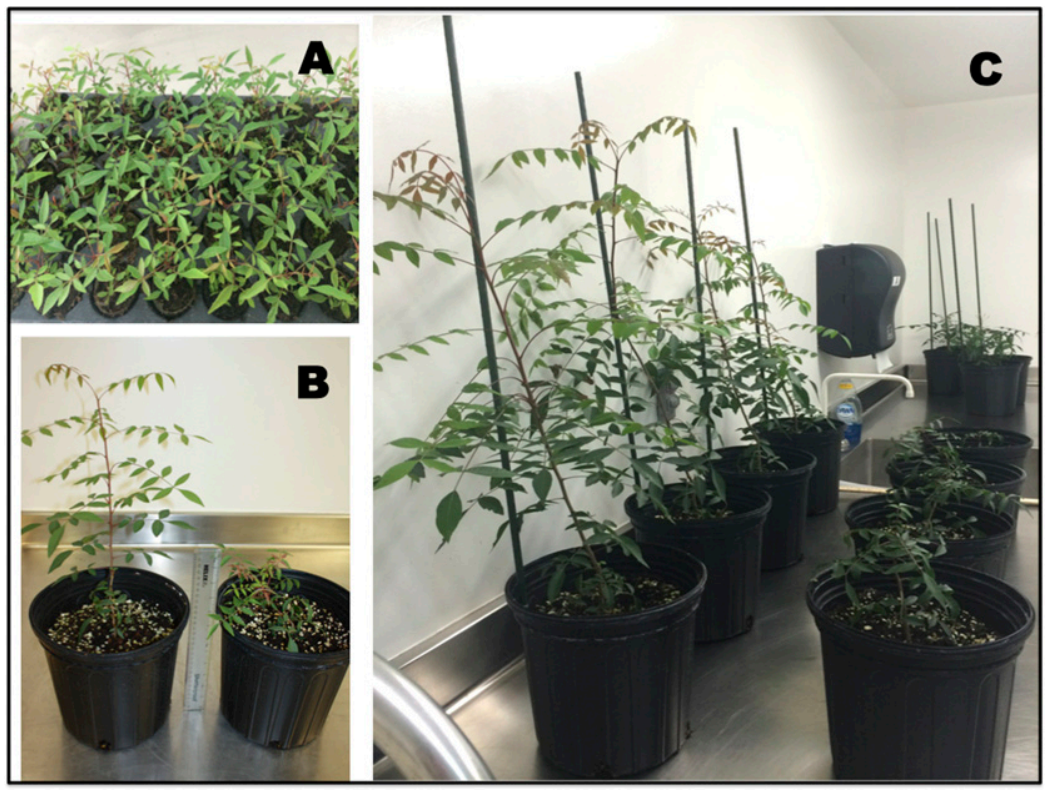

Fig. 5. UCB-1 control trees and trees inoculated with Rhodococcus isolate 1 and Rhodococcus isolate 2. A, Trees were uniform in size and morphology prior to inoculation. B, Comparison of mock-inoculated tree on the left compared with a tree inoculated with Rhodococcus 1 and Rhodococcus 2 . Note the PBTS symptoms such as stunted growth, short internodes, and a light green color. C, Comparison of mock-inoculated trees at left (close to the wall) and trees inoculated with Rhodococcus isolates 1 and 2.

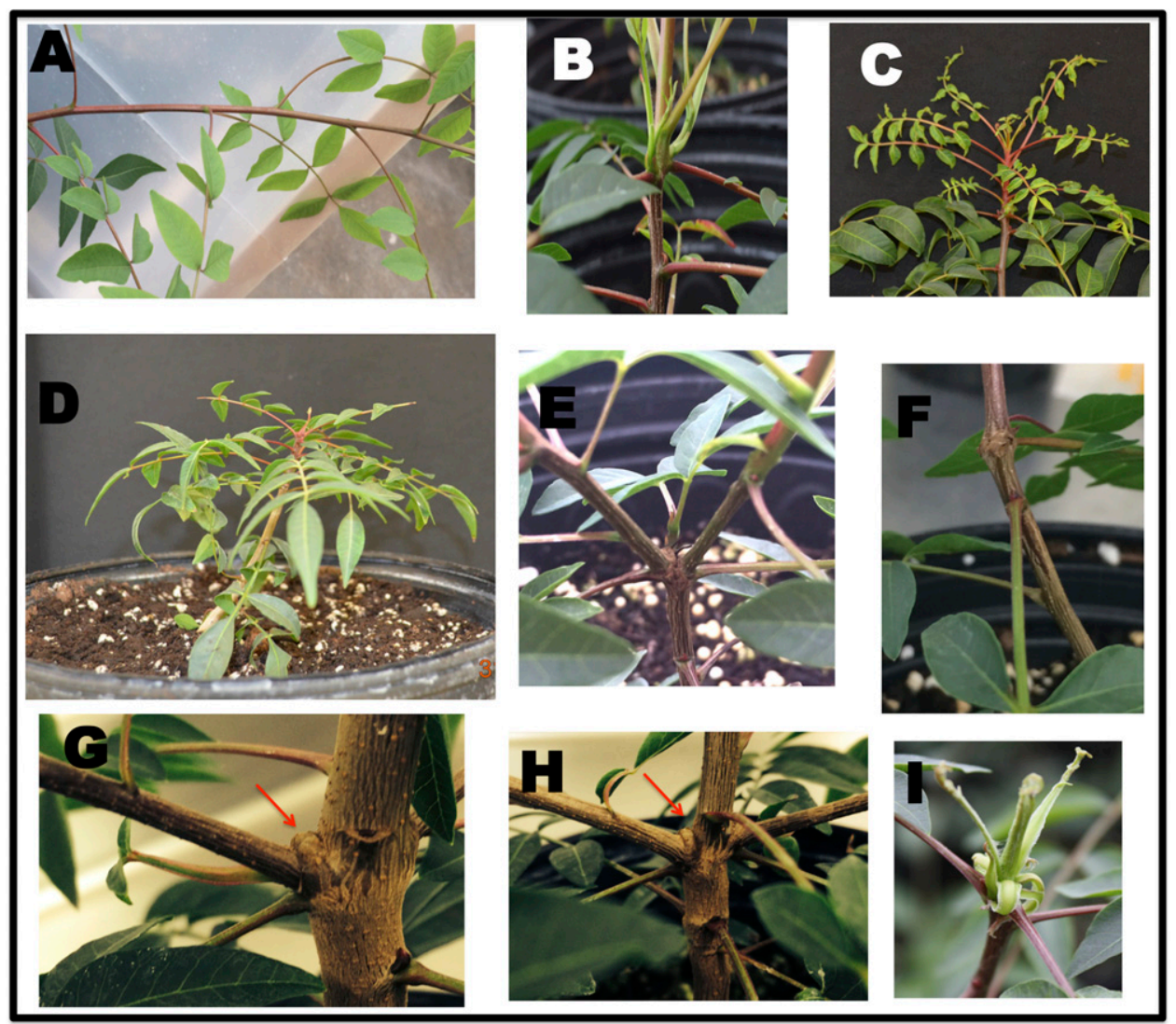

Fig. 6. Shoot symptoms observed on clonal 'UCB-1' trees at 104 days post-inoculation with Rhodococcus isolates 1 and 2. A, Healthy, mock-inoculated UCB-1 tree. B, Sylleptic branching and loss of apical dominance in Rhodococcus 2-inoculated UCB-1 tree. C, Light-green color and reduced leaf size in Rhodococcus 1-inoculated UCB-1 tree. D, Stunting and reduced internode length in Rhodococcus 1 and 2 double-inoculated UCB-1 tree. E, Loss of apical dominance in Rhodococcus 2-inoculated UCB-1 tree. F, Slight lesion forming on Rhodococcus 1 and 2 doubleinoculated UCB-1 tree. G and H, Swollen lateral nodes in Rhodococcus 2-inoculated UCB-1 trees. I, Abnormal apical meristem in Rhodococcus 2-inoculated UCB-1 tree. 
Rhodococcus isolates 1 and 2 were both used for performing Koch's postulates on clonal UCB-1 pistachio trees. Both Rhodococcus isolates 1 and 2 produced symptoms on inoculated UCB-1 rootstock trees, with some symptom differences produced between the two isolates. UCB-1 rootstock trees inoculated with Rhodococcus isolate 2 exhibited sylleptic branching (loss of apical dominance) and swollen nodes (Fig. 6), which were not observed with Rhodococcus isolate 1 . However, overall symptom expression was more pronounced when both isolates were inoculated together. For instance, approximately 80 days post-inoculation, plants inoculated with either isolate began to exhibit significant stunting and shortened internodes, but plants inoculated simultaneously with both Rhodococcus isolates exhibited more severe symptoms at an accelerated rate, with pronounced stunting apparent at 40 days post-inoculation. Symptoms produced after inoculation of UCB-1 clonal trees in a greenhouse

Table 2. Symptoms observed after inoculation from the Rhodococcus isolates

\begin{tabular}{ll}
\hline Rhodococcus isolate & \multicolumn{1}{c}{ Symptoms observed on UCB-1 trees } \\
\hline R1 & $\begin{array}{l}\text { 1. Statistical height difference observed compared } \\
\text { with control UCB-1 trees after } 100 \text { days. }\end{array}$ \\
2. Surface lesions observed. \\
R2 Small leaves light green, cupped leaves and \\
crinkle leaf appearance. \\
1. Loss of apical dominance. \\
2. Sylleptic branching \\
3. Small light green leaves, cupped leaves and \\
crinkle leaf appearance. \\
4. Swollen lateral buds/nodes \\
5. Reduced internode length. \\
6. Abnormal apical meristem formation. \\
7. Statistical height difference observed compared \\
with control after 100 days. \\
1. Loss of apical dominance. \\
2. Severe stunting \\
3. Reduced internode length \\
4. Swollen lateral buds/nodes \\
5. Sylleptic branching \\
6. Smaller light green, cupped leaves and crinkle \\
leaf appearance. \\
7. Surface lesions observed. \\
8. Reduced root morphology.
\end{tabular}

setting were similar to those observed in PBTS-affected field trees and reminiscent of $R$. fascians-induced symptoms on other hosts (Putnam and Miller 2007), including stunting, close internode spacing, sylleptic branching, bushy top morphology, and swollen lateral buds. A few of the inoculated plants developed minor stem lesions (Fig. 6), which is not a symptom generally associated with $R$. fascians infection in other hosts. Currently, the trees are too small for T-budding, so it was not possible to determine if the Rhodococcus isolates are responsible for reduced budding success and bark cracking/lesions at the bud unions observed in two- and three-yearold orchards. A few differences in root morphology, such as poorer root development and root twisting, were observed only on inoculated plants. The less-developed roots of the double-inoculated plants (Fig. 7B) could be due to the lack of vegetative growth and thus less available photosynthates as compared with the control plants. Further studies are in progress to determine if these Rhodococcus isolates directly affect root morphology.

Based on the difference in symptom development between the single-inoculated and double-inoculated plants, it appears that the two Rhodococcus isolates may have a synergistic effect on clonal UCB-1 pistachio rootstock. Microbial synergism involving Rhodococcus spp. is not a new concept. In a study of crude oil biodegradation, the physical and metabolic interactions between Rhodococcus sp. strain F9-D79 and Pseudomonas JA5-B45 allowed a coculture of these microbes to degrade crude oil better than each culture on its own (Van Hamme and Ward 2001). At the moment, it is unknown how the Rhodococcus isolates from this study are functioning together. It is conceivable that the two bacteria may have unique enzymes and metabolic processes that allow for the observed additive effects. It is also possible that each Rhodococcus isolate has specific virulence factors that work together to increase pathogenicity on UCB-1 pistachio trees. Virulence factors required for Rhodococcus fascians strain D188 were identified in both Rhodococcus isolates. It is unknown

Table 3. Data from inoculations with Rhodococcus isolates. Incidence was determined if plants have two or more of the listed symptoms

\begin{tabular}{lcccc}
\hline & Control UCB-1 & R1 & R2 & R1+R2 \\
\hline Trial 1 & $0 / 15$ & N/A & $12 / 15$ & N/A \\
Trial 2 & $0 / 16$ & $12 / 16$ & $14 / 16$ & $13 / 16$ \\
Trial 3 & $0 / 16$ & $15 / 16$ & $14 / 16$ & $13 / 16$ \\
\hline
\end{tabular}

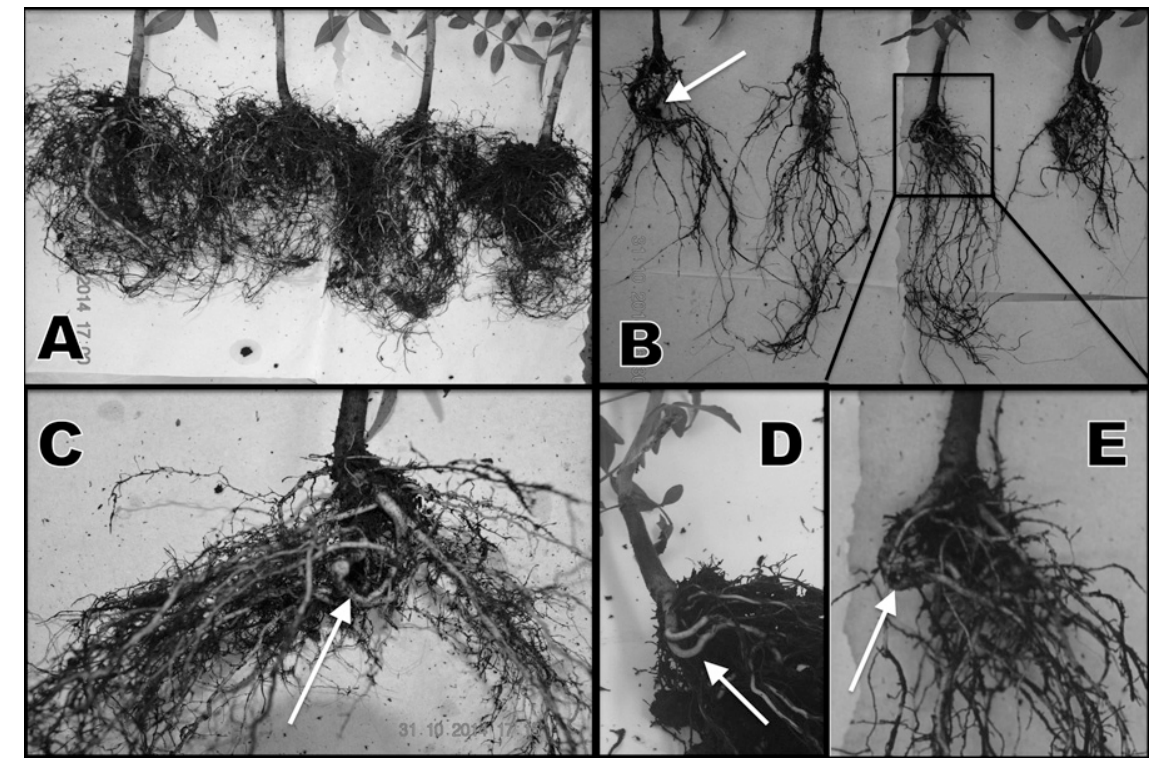

Fig. 7. Root-morphology observed on clonal UCB-1 trees at 104 days post inoculation with Rhodococcus isolates 1 and 2. A, Healthy, mock-inoculated UCB-1 trees. B, Reduced root-development in Rhodococcus 1 and 2 double-inoculated UCB-1 trees. C, Twisted root morphology in Rhodococcus 1 inoculated UCB-1 tree. D and E, Twisted root morphology in Rhodococcus 1 and 2 double-inoculated UCB-1 trees. 
whether these virulence genes are located on a plasmid or if they are incorporated within the genome. Horizontal gene transfer is well documented in many bacterial species including Rhodococcus (Crespi et al. 1992; Dabrock et al. 1994; Le Dantec et al. 2001; Larkin et al. 2005; Ravel et al. 2000). It is plausible that transfer of virulence genes may have occurred in and between these Rhodococcus isolates.

Further research is in progress to understand the synergistic effect of these bacteria. The genomes for both of the Rhodococcus isolates are currently being analyzed for virulence genes and comparison with $R$. fascians. An in-depth microscopy study is in progress to investigate the spatial distribution of the Rhodococcus isolates within UCB-1 tissue and also to identify changes to plant structures associated with Rhodococcus inoculation. Pathogenicity studies with indicator species such as Pisum sativum and Nicotiana benthamiana, as well as other tree crop species, are in progress to determine the specific host range of these Rhodococcus isolates.

\section{Acknowledgments}

The authors would like to thank several pistachio growers for allowing us to tour their affected orchards and providing samples. The authors would also like to thank Dr. Gerald Sims, Dr. David Thompson, Ms. Melodie Putnam, and Dr. John D. Kemp for their critical review of the manuscript. The authors would like to acknowledge the technical help provided by Jordan Martin. The authors would also like to thank NMSU Agriculture Experimental Station and the California Pistachio Research Board for funding this study.

\section{Literature Cited}

Ahmad, R., Ferguson, L., and Southwick, S. M. 2005. Molecular marker analyses of pistachio rootstocks by simple sequence repeats and sequence-related amplified polymorphisms. J. Hortic. Sci. Biotechnol. 80:382-386.

Almehdi, A. A., Parfitt, D. E., and Chan, H. 2002. Propagation of pistachio rootstock by rooted stem cuttings. Sci. Hortic. (Amsterdam) 96:359-363.

Cornelis, K., Ritsema, T., Nijsse, J., Holsters, M., Goethals, K., and Jaziri, M. 2001. The plant pathogen Rhodococcus fascians colonizes the exterior and interior of the aerial parts of plants. Mol. Plant-Microbe Interact. 14:599-608.

Creason, A. L., Vandeputte, O. M., Savory, E. A., Davis, E. W., Putnam, M. L., Hu, E., Swader-Hines, D., Mol, A., Baucher, M., Prinsen, E., Zdanowska, M., Givan, S. A., El Jaziri, M., Loper, J. E., Mahmud, T., and Chang, J. H. 2014. Analysis of genome sequences from plant pathogenic Rhodococcus reveals genetic novelties in virulence loci. PLoS ONE 10.137/journal. pone.0101996.

Crespi, M., Messens, E., Caplan, A. B., Montagu, M., and Desomer, J. 1992. Fasciation induction by the phytopathogen Rhodococcus fascians depends upon a linear plasmid encoding a cytokinin synthase gene. EMBO J. 11: 795-804.

Crespi, M., Vereecke, D., Temmerman, W., Van Montagu, M., and Desomer, J. 1994. The fas operon of Rhodococcus fascians encodes new genes required for efficient fasciation of host plants. J. Bacteriol. 176:2492-2501.

Dabrock, B., Kesseler, M., Averhoff, B., and Gottschalk, G. 1994. Identification and characterization of a transmissible linear plasmid from Rhodococcus erythropolis BD2 that encodes isopropylbenzene and trichloroethane catabolism. Appl. Environ. Microbiol. 60:853-860.

Ferguson, L. 2008. Pistacia vera pistachio. Pages 20-25 in: The Encyclopedia of Fruit and Nuts. J. Janick and R. E. Paull, eds. CABI, Cambridge, MA.

Ferguson, L., Polito, V., and Kallsen, C. 2005. The pistachio tree: Botany and physiology and factors that affect yield. Pages 31-39 in: Pistachio Production Manual, 4th edn. Univ. of California Coop. Ext., Davis, CA.
Gürtler, V., Mayall, B. C., and Seviour, R. 2004. Can whole genome analysis refine the taxonomy of the genus Rhodococcus? FEMS Microbiol. Rev. 28: 377-403.

Kado, C. I., and Heskett, M. G. 1970. Selective media for isolation of Agrobacterium, Corynebacterium, Erwinia, Pseudomonas, and Xanthomonas. Phytopathology 60: 969-976.

Larkin, M. J., Kulakov, L. A., and Allen, C. R. 2005. Biodegradation and Rhodococcus - masters of catabolic versatility. Curr. Opin. Biotechnol. 16:282-290.

Le Dantec, C., Winter, N., Gicquel, B., Vincent, V., and Picardeau, M. 2001 Genomic sequence and Transcriptional analysis of a 23-KB mycobacterial linear plasmid: Evidence for horizontal transfer and identification of plasmid maintenance systems. J. Bacteriol. 183:2157-2164.

Maes, T., Vereecke, D., Ritsema, T., Cornelis, K., Thu, H. N. T., Montagu, M. V. Holsters, M., and Goethals, K. 2001. The att locus of Rhodococcus fascians strain D188 is essential for full virulence on tobacco through the production of an autoregulatory compound. Mol. Microbiol. 42:13-28.

Miller, M. L., and Putnam, M. L. 2010. Sorbaria sorbifolia is a new host for Rhodococcus fascians. Plant Health Progress 10.1094/PHP-2010-0408-01-BR.

Morgan, D. P., Epstein, L., and Ferguson, L. 1992. Verticillium wilt resistance in pistachio rootstock cultivars: Assays and an assessment of two interspecific hybrids. Plant Dis. 76:310-313.

Nikolaeva, E. V., Kang, S., Olson, T., and Kim, S. 2012. Real-time PCR detection of Rhodococcus fascians and discovery of new plants associated with $R$. fascians in Pennsylvania. Plant Health Progress 10.1094/PHP-2012-0227-02-RS.

Pertry, I., Vaclavikova, K., Depuydt, S., Galuszka, P., Spichal, L., Temmerman, W., Stes, E., Schmulling, T., Kakimoto, T., Van Montagu, M. C., Stmad, M., Holsters, M., Tarkowski, P., and Vereecke, D. 2009. Identification of Rhodococcus fascians cytokinins and their modus operandi to reshape the plant. Proc. Natl. Acad. Sci. USA 106:929-934.

Pertry, I., Vaclavikova, K., Gemrotova, M., Spichal, L., Depuydt, S., Temmerman, W., Stes, E., De Keyser, A., Riefler, M., Blondi, S., Novak, O., Schmulling, T., Strnad, M., Tarkowski, P., Holster, M., and Vereecke, D. 2010. Rhodococcus fascians impacts plant development through the dynamic fas mediated production of cytokinin mix. Mol. Plant-Microbe Interact. 23:1164-1174.

Putnam, M. L., and Miller, M. L. 2007. Rhodococcus fascians in herbaceous perennials. Plant Dis. 91:1064-1076.

Quoirin, M., Bona, C., deSouza, E. F., and Schwartsburd, P. B. 2004. Induction of leafy galls in Acacia mearnsii De Wild seedlings infected by Rhodococcus fascians. Braz. Arch. Biol. Technol. 47:339-346.

Ravel, J., Wellington, E. M. H., and Hill, R. 2000. Interspecific transfer of Streptomyces giant linear plasmids in sterile amended soil microcosms. Appl. Environ. Microbiol. 66:529-534.

Serdani, M., Curtis, M., Miller, M. L., Kraus, J., and Putnam, M. L. 2013. Loopmediated isothermal amplification and polymerase chain reaction methods for specific and rapid detection of Rhodococcus fascians. Plant Dis. 97: 517-529.

Spann, T. M., Beede, R. H., and DeJong, T. M. 2007. Preformation in vegetative buds of pistachio (Pistacia vera): Relationship to shoot morphology, crown structure and rootstock vigor. Tree Physiol. 27:1189-1196.

Stes, E., Francis, I., Perty, I., Dolzblasz, A., Depuydt, S., and Vereecke, D. 2013 The leafy gall syndrome induced by Rhodoccus fascians. FEMS Microbiol. Lett. 342:187-194.

Stes, E., Vandeputte, O. M., El Jaziri, M., Holsters, M., and Vereecke, D. 2011. A successful bacterial coup d'etat: How Rhodococcus fascians redirects plant development. Annu. Rev. Phytopathol. 49:69-86.

Van Hamme, J. D., and Ward, O. P. 2001. Physical and metabolic interactions of Pseudomonas sp. strain JA5-B45 and Rhodococcus sp. strain F9-D79 during growth on crude oil and effect of a chemical surfactant on them. Appl. Environ. Microbiol. 67:4874-4879.

Vereecke, D., Cornelis, K., Temmerman, W., Jaziri, M., Van Montagu, M., Holsters, M., and Goethalis, K. 2002. Chromosomal locus that affects pathogenicity of Rhodococcus fascians. J. Bacteriol. 184:1112-1120.

This article was modified on 14 Aug 2017. 
ERRATUM / Volume 99, Number 11, 2015 / PDIS-12-14-1340-RE

In the article "First Report of Rhodococcus Isolates Causing Pistachio Bushy Top Syndrome on 'UCB-1' Rootstock in California and Arizona" by R. A. Stamler, J. Kilcrease, C. Kallsen, E. J. Fichtner, P. Cooke, R. J. Heerema, and J. J. Randall, a typo was made in regards to a GenBank accession number. On page 1471 , it should state "....and isolate 1 generated fasA (putative p450 monooxygenase) sequence that had $100 \%$ identity to $\mathrm{pFiD} 188$ (Accession No. KP274062). At the time of publication, no fasA sequence was generated for isolate 2." 